\title{
Partial trisomy $2 q 33.3-q 37.3$ in a patient with an inverted duplicated neocentric marker chromosome
}

\author{
Ruiyu Ma ${ }^{1}$, Ying Peng ${ }^{1}$, Yanghui Zhang ${ }^{1}$, Yan Xia ${ }^{1}$, Guizhi Tang ${ }^{1}$, Jiazhen Chang ${ }^{1}$, Ruolan Guo ${ }^{1}$, Baoheng Gui ${ }^{1}$, \\ Yanru Huang ${ }^{1}$, Chen Chen ${ }^{1,2}$, Desheng Liang ${ }^{1}$ and Lingqian $\mathrm{Wu}^{1 *}$
}

\begin{abstract}
Background: Increasing number of cases with small supernumerary marker chromosomes (sSMCs) without centromeric DNA and dozens of cases with trisomy 2q3 have been reported in recent years. However, cases of simultaneous SSMC and partial trisomy of chromosome $2 \mathrm{q}$ have been rarely described.

Results: We report the case of a young girl patient with growth retardation and mild facial features due to a partial trisomy 2q33.3-37.3. The $34.3 \mathrm{Mb}$-duplication of the 2q33.3 to q37.3 region found in the patient constituted a supernumerary inverted duplicated neocentric marker chromosome.

Conclusions: This is the first case of a patient with partial trisomy 2q33.3-37.3 presenting an inverted duplicated neocentric marker chromosome. Based on the case, this study will help further understanding the genotype/ phenotype correlations of partial 2q3 duplication and exploring the relationship between neocentric SSMC and human diseases.
\end{abstract}

Keywords: Growth retardation, Neocentromere, Partial trisomy 2q3, SNP array, sSMC

\section{Background}

Small supernumerary marker chromosomes (sSMCs), which are detected in approximately $0.075 \%$ of prenatal specimens and $0.044 \%$ of newborn infants [1], are defined as structurally abnormal chromosomes that cannot be unambiguously identified or characterized by conventional banding cytogenetics alone [2]. In general, they are equal or smaller in size than chromosome 20 of the same metaphase spread. According to the literature, sSMCs are most often found in mentally retarded patients $(0.288 \%)$, and followed by infertile patients $(0.125 \%)$ [1]. sSMCs constitute a morphologically heterogeneous group appearing as different types of inverted duplicated-, ring-, or minute chromosomes. During meiosis and mitosis, the centromere controls the segregation of the genetic material. In the absence of endogenous centromeres, the rearranged chromosomes would either be lost or become acentric.

\footnotetext{
* Correspondence: wulingqian@sklmg.edu.cn

${ }^{1}$ State Key Laboratory of Medical Genetics, Central South University, 110 Xiangya Rd, Changsha, Hunan 410078, China

Full list of author information is available at the end of the article
}

While most human marker chromosomes appear to contain normal human centromeres with detectable alpha satellite DNA [3], stable sSMC that do not contain any known centromeric DNA have been increasingly reported in recent years. These sSMC contain a region called "neocentromere" acting as a functional centromere that has not been known to have a centromere function previously. In this report, we present a case of partial trisomy $2 \mathrm{q}$ in a girl with neocentric sSMC. To the best of our knowledge, pure partial trisomy of chromosome $2 \mathrm{q} 3$ with the absence of associated monosomy is rare. This is the first report on the molecular cytogenetic characterization of a partial trisomy 2q33.3-37.3 with an inverted duplicated neocentric marker chromosome.

\section{Case presentation}

\section{Case report}

The patient, a 2-year-old girl, was referred to our center because of growth retardation, distinctive facial features, and chromosomal abnormalities identified at another hospital. She was delivered at term via cesarean section as the first child to non-consanguineous Chinese parents. 
Contributory family history was absent. Her weight at birth was $2.2 \mathrm{~kg}$ ( 0.4th percentile), and no significant hypoxia, jaundice, or other complications were recorded at birth. The parents were 26 (mother) and 31 (father) years of age at the time of the birth. They were both healthy with normal karyotypes. Approximately 40 days into pregnancy, the mother had taken traditional Chinese medicine because of high temperature. After the baby was born, she had jaundice and was treated for six days. Although she could sit alone without assistance at nine months of age, she is still unable to walk alone at age 2, suggesting a delay in psychomotor milestones. Speech retardation also existed because she cannot have a dialogue with others except for some simple words such as "Mom" and "Grandma." Physical examination showed a height of $86 \mathrm{~cm}$ ( 50th percentile) and weight of $11 \mathrm{~kg}$ ( 25th percentile). She had mild facial dysmorphic features, including ocular hypertelorism, epicanthus, upslanted palpebral fissures, flat nasal bridge, and protruding ear. No other obvious abnormalities were observed to date.

\section{Results}

Analysis of GTG-banded chromosomes in the proposita revealed a supernumerary marker in all analyzed metaphases; however, a $2 \mathrm{q}$ deletion was observed (Figure 1a). C-banding (Figure 1b) showed the absence of centromeric heterochromatin in the marker chromosome, suggesting the presence of a neocentric sSMC. The parents' karyotypes were normal, indicating a de novo marker chromosome. SNP array analysis detected a $34.3 \mathrm{Mb}-$ duplication (nt.208775856-243044147) of the 2q33.3 to q37.3 region (Figure 1c). The proximal breakpoint was mapped within a $7.5 \mathrm{~kb}$ region between SNPs rs2621470 and rs2621472 (nt.208768367-208775856) at 2q33.3, while the distal breakpoint was located in the last SNP rs12469535 at 2qter (position 243044147). Considering the result of banding cytogenetics and copy number variation analysis, we supposed that this supernumerary marker chromosome arose from chromosome 2. We confirmed the chromosome 2 origin with FISH analysis using a BAC clone RP11-526 L8 (orange) within the duplicated region in the patient and her parents (Figure 1d, e, and f). FISH studies also showed that the marker chromosome has some features of an isochromosome. The combined results proved that the supernumerary marker chromosome was derived de novo from chromosome 2 and corresponded to an inverted duplication conformation. Finally, we described the karyotype of the proposita as a

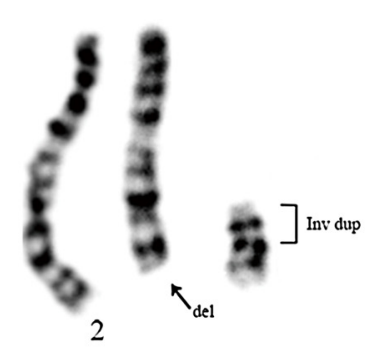

b

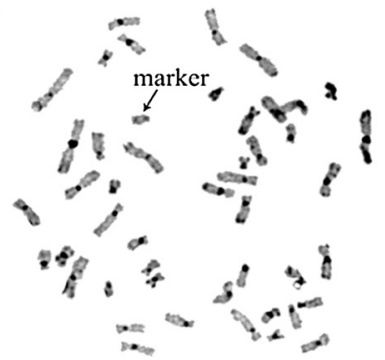

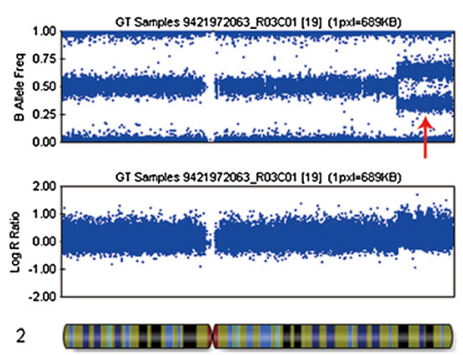
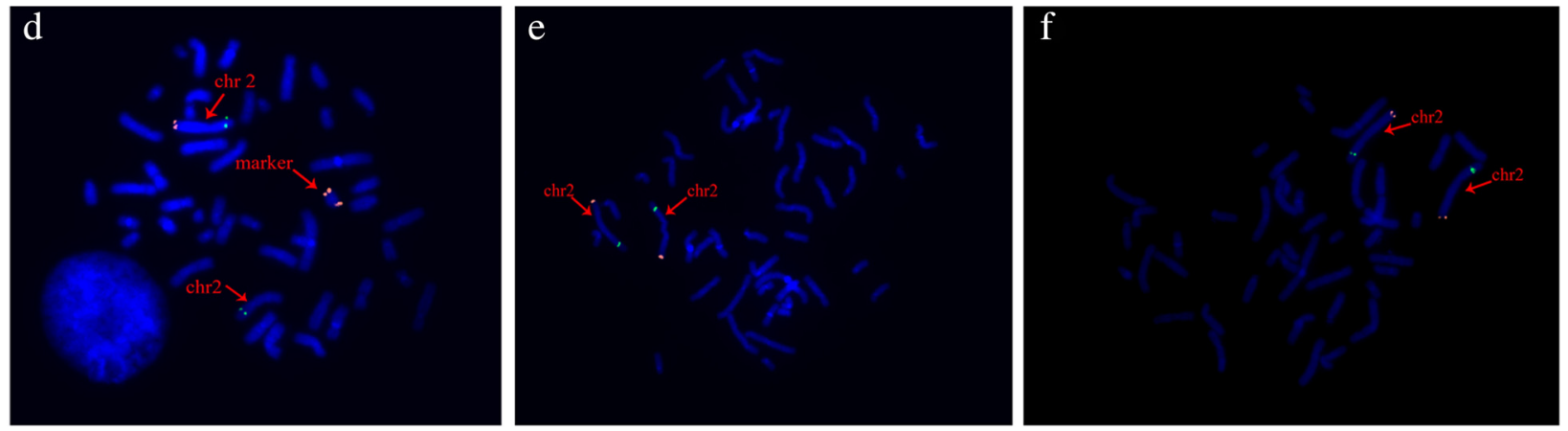

Figure 1 Cytogenetic and molecular results. (a) G-banding partial karyotypes of the patient, indicating a terminal deletion of 2q, accompanying with a marker chromosome. (b) C-banding showing no centromeric heterochromatin. (c) Copy number variation analysis for individual SNP loci along chromosome 2 using Illumina Human OmniZhongHua-8 Beadchip. B Allele Frequency and Log R show a gain of 34,268,291 bp (nt. 208775856-243044147) in terminal end of 2q (Red arrow ). (d) FISH results of the patient. FISH using RP11-526 L8 (orange) at 2q37.3 as a test probe and RP11-119B15 (green) at 2p22.3 as a control probe, showing an orange signal and a green signal on each of the two copies of only one chromosome 2, while the other one lacking the orange signal. Two orange hybridization signals for test probe on the SMC corresponding to an inverted duplication marker. (e, f) FISH results of the parents showing one hybridization signal for each probe on the two normal chromosomes 2. 
47, XX, del(2)(pter $\rightarrow$ q33.3), +neo(2) (qter $\rightarrow$ q33.3 $\rightarrow$ neo $\rightarrow$ q33.3 $\rightarrow$ qter $)$.

\section{Discussion}

Till date, dozens of cases with trisomy $2 \mathrm{q} 3$ have been reported in the literature, most of which are associated with monosomy of another chromosome segment [4]. Majority are the result of an abnormal segregation of the parents chromosome rearrangement. In contrast, pure duplication of $2 \mathrm{q} 3$ is relatively rare. In the present study, we report a case of pure partial trisomy 2q33.3-q37.3. The proband, a 2-year-old girl displays mild facial dysmorphic features and has a delayed development similar to the known clinical features of the $2 \mathrm{q} 3$ duplication syndrome [5-7]. To our best knowledge, only 14 cases with isolated duplications of $2 \mathrm{q}$ overlapping 2q33-2qter have been previously described [4,8-19]. Majority of these cases (Table 1) are de novo and an inverted duplication is the most common form of rearrangement. Patients reported with duplication of 2q33-2qter also have similar clinical phenotypes, including variable developmental delays, facial and visceral anomalies, and trunk and limb malformations. Mild to moderate growth and mental retardation were documented in all cases except in the one without growth retardation [11]. Characteristic facial features were noticed in the neonatal period, including hypertelorism and epicanthic folds, broad flat nasal bridge, anteverted nostrils, long philtrum, thin upper lip, low-set ears, Cupid's bow lip, and micrognathia. Minor visceral anomalies reported in some patients mainly involve cardiac, kidney or brain defects, and external genitalia malformations. In addition, common acral anomalies include fifth-finger clinodactyly, brachydactyly, and abnormal palmar or flexion creases. Overall, the clinical phenotypes of our proposita in this study are gentle and equivalent to those in the literature, yet visceral and limb malformations were not observed. Compared with other chromosome disease syndromes, most phenotypes of the $2 \mathrm{q} 3$ duplication syndrome are shared with other syndromes.

In this report, we describe the special rearrangement form in our patient, a de novo inverted duplication marker chromosome verified by cytogenetic and molecular analysis. Because the karyotype 47, XX, del(2) (pter $\rightarrow$ q33.3), +mar were detected in 100\% cells and no heterochromatic region was found, we speculated that the marker carried "a newly derived centromere" to support its stability. The first human neocentromere lacking alpha satellite DNA was discovered by Voullaire in 1993 [20]. Since then, increasing numbers of new cases with neocentromere have been reported in the literature. Based on his analysis of 93 cases of neocentromere formation, Marshall et al. suggested "hotspots" of neocentromere formation. They found that certain regions of some chromosomes seemed particularly prone to form neocentromeres, such as $3 \mathrm{q}, 8 \mathrm{p}, 13 \mathrm{q}$, and $15 \mathrm{q}$, although the specific mechanism remains unclear [21]. Earlier studies have reported several similar cases with neocentromere markers that are originated from other chromosomes (Table 2). A review of these cases revealed that the major type of rearrangement of these mirror-image markers was terminal deletion accompanying with inverted duplication, which was also applicable to the present case. Case 6 was a little different

Table 1 Reported cases with pure distal trisomy 2q overlapping 2q33-2qter

\begin{tabular}{|c|c|c|c|c|c|c|}
\hline \multirow[t]{2}{*}{ References } & \multirow{2}{*}{$\begin{array}{l}\text { Duplication } \\
\text { size }\end{array}$} & \multirow{2}{*}{$\begin{array}{l}\text { Type of } \\
\text { rearrangement }\end{array}$} & \multirow[t]{2}{*}{ Origin } & \multicolumn{3}{|l|}{ Phenotype } \\
\hline & & & & Developmental delay & $\begin{array}{l}\text { Facial/visceral } \\
\text { anomalies }\end{array}$ & $\begin{array}{l}\text { Trunk and limb } \\
\text { malformations }\end{array}$ \\
\hline Dennis et al., [8] & $2 q 33-2 q 37$ & Ins 12q23 & Pat. & + & $+/+$ & + \\
\hline Yu and Chen, [9] & $2 q 34-2 q 37$ & Inv dup & De novo & + & $+/-$ & + \\
\hline Kyllerman et al., [10] (2 cases) & 2q34-2qter & Inv dup & Pat. & + & $+/+$ & + \\
\hline $\begin{array}{l}\text { Dahoun-Hadorn and } \\
\text { Bretton-Chappuis, [11] }\end{array}$ & 2q35-2qter & Inv dup & De novo & $+^{*}$ & $+/+$ & + \\
\hline Romain et al., [12] & $2 q 33.1-2 q 35$ & Dir dup & De novo & + & $+/-$ & + \\
\hline Fritz et al., [13] & $2 q 35-2 q 37.1$ & Ins $17 q 25$ & De novo & + & $+/+$ & + \\
\hline Seidahmed et al., [14] & $2 q 32-2 q 37$ & Inv dup & De novo & + & $+/+$ & + \\
\hline Angle et al., [15] & 2q34-2qter & Inv dup & Mat. & + & $+/+$ & + \\
\hline Bonaglia et al., [16] & $2 q 33-2 q 37$ & Inv dup & De novo & + & $+/+$ & + \\
\hline Bird and Mascarello, [17] & $2 q 33.1-2 q 37.1$ & Dir dup & De novo & + & $+/+$ & + \\
\hline Slavotinek et al., [18] & $2 q 33-2 q 37.3$ & Inv dup & De novo & + & $+/-$ & + \\
\hline Hermsen et al., [4] & $2 q 35-q 37.3$ & Trans dir dup & De novo & + & $+/-$ & + \\
\hline Pietrzak et al., [19] & $2 q 35-q 36$ & Sup $r$ & De novo & + & $+/-$ & + \\
\hline
\end{tabular}

Ins, insertion; Inv dup, inverted duplication; Dir dup, direct duplication; Trans dir dup, translocation direct duplication; Sup r, supernumerary ring; Mat., maternal; Pat., paternal.

*The mentally retarded child presented with comparable facial anomalies, hypospadias and bilateral cryptorchidism, but without growth retardation. 
Table 2 Comparison of similar cases with inverted duplicated neocentric sSMC

\begin{tabular}{|c|c|c|c|c|}
\hline Case number & $\begin{array}{l}\text { Karyotype and grade } \\
\text { of mosaicism }\end{array}$ & Type of rearrangement & $\begin{array}{l}\text { Karyotype } \\
\text { of parents }\end{array}$ & $\begin{array}{l}\text { Reference on sSMC } \\
\text { homepage [11] }\end{array}$ \\
\hline 1 & 47,XX,del(1)(q32),+der(1)(qter $\rightarrow$ q32::q32 $\rightarrow$ qter)[100\%] & Terminal deletion + Inv dup(possibly) & NOR & $01-\mathrm{N}-\mathrm{q} 32 / 1-1$ \\
\hline 2 & 47,XX,del(9)(p12),+der(9)(pter $\rightarrow$ p12::p12 $\rightarrow$ pter)[100\%] & Terminal deletion + Inv dup & NOR & $09-N-p t 12 / 1-1$ \\
\hline 3 & 47,XY,del(11)(q22),+der(11)(qter $\rightarrow$ q22::q22 $\rightarrow$ qter)[100\%] & Terminal deletion + Inv dup & NOR & $11-\mathrm{N}-\mathrm{qt} 22 / 1-1$ \\
\hline 4 & $\begin{array}{l}\text { 47,XX,del(13)(q32.3),+der(13)(qter } \rightarrow \text { q32.3::q32.3 } \rightarrow \text { qter) } \\
{[100 \%]}\end{array}$ & Terminal deletion + Inv dup & NA & $13-\mathrm{N}-\mathrm{qt} 32.3 / 2-1$ \\
\hline 5 & $\begin{array}{l}47, X X \text {,del(14)(q32.1),+der(14)(qter } \rightarrow \text { q32.1::q32.1 } \rightarrow \text { qter }) \\
{[100 \%]}\end{array}$ & Terminal deletion + Inv dup & NOR & $14-\mathrm{N}-\mathrm{qt} 32.1 / 1-1$ \\
\hline 6 & $47, X Y, i(16)(q 10),+\operatorname{der}(16)(p 13.3 p 11.2)[100 \%]$ & Deletion + Iso & NOR & $16-\mathrm{N}-\mathrm{p} 11.2 / 1-1$ \\
\hline 7 & 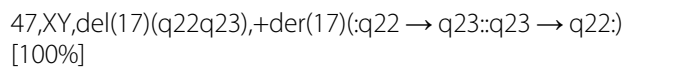 & Interstitial deletion + Inv dup & NOR & 17-N-qt22/1-1 \\
\hline 8 & $\begin{array}{l}47, X X \text {,del(20)(p11.2), +der(20)(pter } \rightarrow \text { p1 1.2::p1 1.2 } \rightarrow \text { pter }) \\
{[100 \%]}\end{array}$ & Terminal deletion + Inv dup & NOR & $20-\mathrm{N}-\mathrm{pt} 11.2 / 1-1$ \\
\hline 9 & 47,XX,del(2)(q33.3),+der(2)(qter $\rightarrow$ q33.3::q33.3 $\rightarrow$ qter)[100\%] & Terminal deletion + Inv dup & NOR & the present case \\
\hline
\end{tabular}

Inv dup, inverted duplication; Iso, isochromosomes; NA, not available for testing; NOR, normal.

from other cases for the presence of an isochromosome for the long arm of chromosome 16 and an acentric neocentric marker derived from the short arm of chromosome 16. Yet essentially, the likely mechanism of this complex rearrangement is also a deletion accompanying with inverted duplication. All the markers of these cases formed almost de novo. Mental retardation or delayed psychomotor development combined with physical handicaps could be observed in all probands of these cases, and the other clinical features of each proband were corresponding to the characteristics of each trisomy syndrome fundamentally. In our study, the neocentric sSMC is an inverted duplication chromosome derived from the distal region of chromosome 2q. To date, there are only two constitutional neocentromere cases with sSMC involving chromosome 2 described in the literature: one involving a ring marker chromosome from an interstitial deletion (paracentric) and the other a supernumerary ring. To the best of our knowledge, in partial trisomy $2 \mathrm{q}$ syndrome, this form of an inverted duplication neocentric chromosomal rearrangement with a deleted chromosome complementary for the region of duplication has not been previously reported.

Considering the mechanism of neocentric sSMC formation, many different theories have been proposed. At present, ring and inv dup shaped neocentric sSMC are mainly reported. Ring neocentric chromosomes are mainly due to McClintock mechanism [22], which is in connection with a balanced situation in the carriers. For formation of inv dup shaped sSMC, as summarized by Liehr et al. [23], Marshall et al. [21] and Murmann et al. [24], these markers may form either in meiosis or mitosis. The majority are based on a U-type exchange between two homologous chromosomes at meiosis I, resulting in tetrasomy for the terminal chromosomal region present on the marker, while the remaining inv dup markers may come from other mechanisms leading to partial trisomy of that region in the genome. Our patient carries an apparent terminal deletion at chromosome $2 \mathrm{q}$ accompanied with a neocentric inverted duplication chromosome. Because no chimerism was found in our patient and in other patient reports with analogous rearrangements, we believed that the break could not occur during a mitotic event, otherwise mosaicism would be observed. In view of the above facts, we speculate that the most plausible explanation is a distal U-type exchange occurring between two chromatids of the same chromosome at meiosis II (Figure 2). A double-chromatid break occurred when the sister chromatids were about to separate during the second meiosis. Subsequently, two broken chromatids would be dragged into two hemizygotes in effect of traction, while the acentric chromosomal fragment resulting from crossover mistakes of the chromatids might segregate with one of them. Neocentromerization occurred at any location once the inv dup marker chromosome had been formed. After fertilization and subsequent replication in early zygote development, the endpoint would be partial trisomy in the form of the stable marker. This is the situation seen in our patient. To validate our speculation, we used simple quantitative fluorescent polymerase chain reaction (QF-PCR) to perform short tandem repeat analysis (Figure 3). Copy number variation occurring after the homologous chromosomes separation in meiosis can generate allele homologous repeats. Moreover, in trisomic diallelic cases, two out of three chromosomes share the same loci so that a pattern of 2:1 ratio between two peaks will be detected which coincides with our result. According to the evaluation criteria of QF-PCR [25], we can consider that the extra chromosome segment in our patient results from homologous paternal allele duplication. However, due to the lack of a satellite centromeric specific probe, the specific location of the neocentromere cannot be 


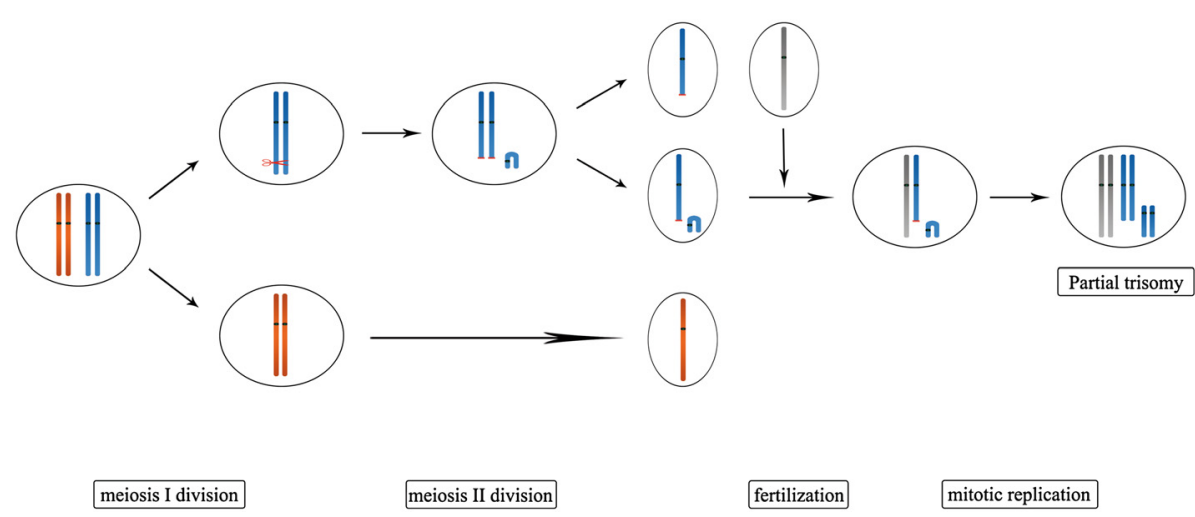

Figure 2 Possible mechanisms for the formation of neocentric marker chromosome in the patient. Chromatids breakage (red scissors) and a distal U-type exchange happened before sister chromatid separation during the meiosis II. Neocentromerization occurred once breakage happened. Deep color ovals are the centromeres, and the same one on the acentric fragment is neocentromere. The broken ends (red wave) of the centric fragment could be stabilized by telomere restitution. After zygogenesis and subsequent replication the result would be partial trisomy for the duplicated fragment.

determined; whether it is an isochromosome is also unknown.

Among the reported cases, majority of neocentric marker chromosomes were derived from chromosomal arms or telomeric regions [21,26,27] containing a higher density of euchromatic sequences than centric sSMC. This may explain the strong correlation ( $\sim 90$ percentile) between neocentric sSMC and abnormal phenotype [28]. According to the literature, the critical region correlating with clinical features, including facial dysmorphism, postnatal growth retardation, syndactyly, and visceral hypoplasia, has been preliminarily mapped within the 2q34-qter interval [29]. We reviewed 56 virulence genes contained in the 2q33-2qter duplication region observed in our patient and found that four genes may determine the phenotype: TM4SF2O (OMIM:615404), PDE6D(OMIM:602676), HDAC4(OMIM:605314), and KIF1A(OMIM:601255). Among patients with developmental delay, speech impairment, and/or brain imaging abnormalities, a heterozygous $4 \mathrm{~kb}$-deletion of the TM4SF 20 was identified by
Wiszniewski et al. [30]. Thomas et al. reported a PDE6D mutation in two siblings with Joubert syndrome displaying intrauterine growth retardation, facial dysmorphism, postaxial polydactyly of the feet, syndactyly, and other symptoms [31]. Patients with brachydactyly mental retardation syndrome resulting from a mutation, deletion, or interruption in HDAC4 have been described with an analogous phenotype in a report [32]. Mutations in KIF1A caused nonsyndromic intellectual disability in a patient described by Hamdan et al. [33]. The phenotype associated with these four disease-causing genes are overlapping with the one observed in our patient, although no syndactyly and visceral anomalies were seen in our patient. This discrepancy may be due to the fact that the pathogenicity of genes is mainly determined by interrupted or deleted variants rather than duplications. Genes are dosagesensitive and become defective by loss rather than by gain of function. Furthermore, we also noticed that the chromosome 2q35 duplication syndrome (OMIM:185900) was located within the duplication interval in our

\section{D2S1279}

D2S1338
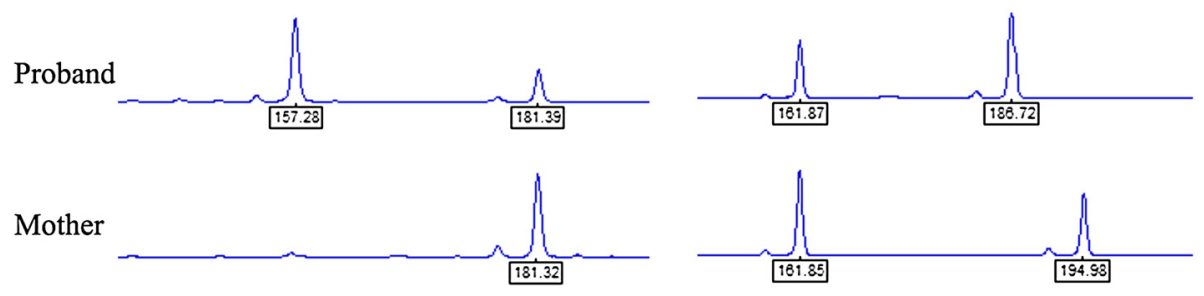

Father
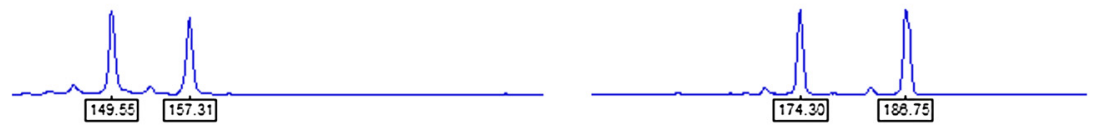

Figure 3 Microsatellite analysis of markers D2S1279 and D2S1338 on ABI 3100 genetic analyser. The 2:1 ratio between two fluorescent peaks areas in the proband indicated that she inherited a double dosage of one of the paternal alleles. 
patient. This syndrome is characterized by syndactyly type I and Philadelphia-type craniosynostosis. Klopocki et al. [34] identified a $59 \mathrm{~kb}$ microduplication at the $I H H$ (OMIM:600726) locus on chromosome 2q35 and a minimum region of $9.1 \mathrm{~kb}$ region located $40 \mathrm{~kb} 5^{\prime}$ of the $I H H$ gene, in three families associated with variable degrees of syndactyly and craniosynostosis. Our patient carries this microduplication but does not have these characteristics, showing only mild facial dysmorphism and delayed psychomotor development. One reason may be because of the broader duplicated region which encompasses more genes and gene regulatory regions. A large fragment repeat of the gene regulatory region may act as a group affecting gene expression differently, by controlling the expression of genes either within the region or outside, therefore, resulting in different phenotypes. Moreover, this novel rearrangement may lead to chromatin changes, and the presence of the neocentromere in the marker chromosome may influence gene expression [35]. Finally, it is difficult to explain a clear genotype/phenotype correlation for the $2 \mathrm{q} 3$ duplication syndrome because of variable clinical situations and the ambiguous breakpoints. The specific pathogenesis remains to be explored with precise breakpoint position mapping and related functional studies.

\section{Conclusions}

In conclusion, we report the first case of a patient with partial trisomy 2q33.3-37.3 presenting an inverted duplicated neocentric marker chromosome. Our patient had only facial dysmorphism and developmental delay as opposed to the previously described phenotype found with pure partial trisomy of chromosome $2 \mathrm{q} 3$. We defined the origin of the duplication fragment and analyzed the rearrangement and the patient's phenotype which will help further understanding of the genotype/phenotype correlations of partial $2 \mathrm{q} 3$ duplication and exploring the relationship between neocentric sSMC and human diseases.

\section{Methods}

Cytogenetic analyses were performed on metaphase chromosomes of the patient and her parents derived from peripheral blood lymphocytes cultures. G-banding (400-550 bands) was performed first, according to the standard procedure. However, to further determine whether sSMCs found in GTG-banding karyotype contained centromeres, we performed C-banding which highlighted heterochromatic regions.

Genomic DNA of the patient was extracted from fresh peripheral blood using the standard phenol/chloroform method. SNP array analysis of the extracted DNA was performed using the Human OmniZhongHua-8 Beadchip (Illumina, San Diego, CA) with an average resolution of $3.34 \mathrm{~Kb}$. The arrays were scanned on a microarray scanner and analyzed using GenomeStudio (cnv Partition Plug-in v3.1.6) software. The operative procedures mentioned above were all performed according to the manufacturer's recommended protocols (www.illumina.com).

In order to verify the possible pathogenic copy number variations and determine their origin, FISH analysis was performed on metaphase or interphase chromosomes from the patient and her parents. We used two BAC clone probes, RP11-526 L8 (orange) at 2q37.3 as a test probe, and RP11-119B15 (green) at 2p22.3 as a control probe.

\section{Consent}

Written informed consent was obtained from the parents of the patient for publication of this Case report. A copy of the written consent is available for review by the Editor-in-Chief of this journal.

\section{Abbreviations}

SSMCS: Small supernumerary marker chromosomes; SNP array: Single nucleotide polymorphism array; FISH: Fluorescent In Situ Hybridization; BAC: Bacterial artificial chromosome; QF-PCR: Quantitative fluorescent polymerase chain reaction.

\section{Competing interests}

The authors declare that they have no competing interests.

\section{Authors' contributions}

RM wrote the manuscript, carried out the microarray and the interpretation of SNP array results; YP referred the patient for study and coordinated the clinical analysis of the patient; YZ, YX and GT performed the cytogenetic and FISH studies and diagnoses; JC and RG was involved in SNP array analysis; BG and YH participated in QF-PCR design and analyses; CC coordinated the study; JC, GR and DL revised the manuscript critically for important intellectual content; LW initiated the study, made substantial contribution to conception design and revised the manuscript critically. All authors read and approved the final manuscript.

\section{Acknowledgements}

This study was supported by grants from the National Key Basic Research Program of China (2012CB944600), the National Key Technology R\&D Program of China (2012BAI09B05) and the postdoctoral research fund in Hunan Province(2014RS4007). We thank the family members of the patient for their participation in our study.

\section{Author details}

${ }^{1}$ State Key Laboratory of Medical Genetics, Central South University, 110 Xiangya Rd, Changsha, Hunan 410078, China. ${ }^{2}$ Department of Pediatrics, Xiangya Hospital, Central South University, Changsha, Hunan P.R, China.

Received: 18 December 2014 Accepted: 15 January 2015

Published online: 06 February 2015

\section{References}

1. Liehr T, Weise A. Frequency of small supernumerary marker chromosomes in prenatal, newborn, developmentally retarded and infertility diagnostics. Int J Mol Med. 2007;19:719-31.

2. Shaffer LG, MCGowan-Jordan J, Schmid M. ISCN 2013: An International System for Human Cytogenetic Nomenclature (2013). Switzerland: S Karger AG; 2013.

3. Choo KHA. The centromere. Oxford: Oxford University Press; 1997.

4. Hermsen MA, Tijssen M, Acero IH, Meijer GA, Ylstra B, Toral JF. High resolution microarray CGH and MLPA analysis for improved genotype/ phenotype evaluation of two childhood genetic disorder cases:ring chromosome 19 and partial duplication 2q. Eur J Med Genet. 2005;48:310-8.

5. Francke U. Clinical syndromes associated with partial duplications of chromosomes 2 and 3: dup(2p), dup(2q), dup(3p), dup(3q). Birth Defects Orig Artic Ser. 1978;14:191-217. 
6. De Grouchy J, Turleau C. Clinical atlas of human chromosomes. New York: John Wiley \& Sons; 1984.

7. Schinzel A. Catalogue of unbalanced chromosome translocations in man. New York: de Gruyter; 1984

8. Dennis NR, Neu RL, Bannerman RM. Duplication 2q33 leads to 2q37 due to paternal ins (12;2) translocation. Am J Med Genet. 1978;1:271.

9. $\mathrm{Yu} \mathrm{CW}$, Chen $\mathrm{H}$. De novo inverted tandem duplication of the long arm of chromosome 2(q34 leads to q37). Birth Defects Orig Artic Ser. 1982;18:311-20.

10. Kyllerman M, Wahlström J, Westerberg B, Gustavson KH. Delineation of a characteristic phenotype in distal trisomy 2q. Helv Paediatr Acta. 1984;39:499-508

11. Dahoun-Hadorn S, Bretton-Chappius B. De novo inversion-duplication of 2q35-2qter without growth retardation. Ann Genet. 1992;35:55-7.

12. Romain DR, Mackenzie NG, Moss D, Columbano-Green LM, Smythe RH, Parfitt RG, et al. Partial trisomy for $2 q$ in a patient with dir dup(2) (q33.1q35). J Med Genet. 1994;31:652-3.

13. Fritz B, Müller-Navia J, Hillig U, Köhler M, Aslan M, Rehder H. Trisomy 2q35-q37 due to insertion of 2q material into 17q25: clinical, cytogenetic, and molecular cytogenetic characterization. Am J Med Genet. 1999;87:297-301.

14. Seidahmed MZ, Rooney DE, Salih MA, Basit OB, Shaheed MM, Abdullah MA, et al. Case of partial trisomy $2 \mathrm{q} 3$ with clinical manifestations of MarshallSmith syndrome. Am J Med Genet. 1999;85:185-8.

15. Angle B, Hersh JH, Yen F, Christensen KM. Case of partial duplication 2q3 with characteristic phenotype: rare occurrence of an unbalanced offspring resulting from a parental pericentric inversion. Am J Med Genet. 2000;91:126-30.

16. Bonaglia MC, Giorda R, Poggi G, Raggi ME, Rossi E, Baroncini A, et al. Inverted duplications are recurrent rearrangements always associated with a distal deletion: description of a new case involving 2q. Eur J Hum Genet. 2000;8:597-603.

17. Bird LM, Mascarello JT. Chromosome 2q duplications: case report of a de novo interstitial duplication and review of the literature. Am J Med Genet. 2001;100:13-24.

18. Slavotinek AM, Boles D, Lacbawan F. A female infant with duplication of chromosome 2q33 to 2q37.3. Clin Dysmorphol. 2003;12:251-6.

19. Pietrzak J, Mrasek K, Obersztyn E, Stankiewicz P, Kosyakova N, Weise A, et al. Molecular cytogenetic characterization of eight small supernumerary marker chromosomes originating from chromosomes 2, 4, 8, 18, and 21 in three patients. J Appl Genet. 2007:48:167-75.

20. Voullaire LE, Slater HR, Petrovic $V$, Choo KH. A functional marker centromere with no detectable alpha-satellite, satellite III, or CENP-B protein: activation of a latent centromere? Am J Hum Genet. 1993;52:1153-63.

21. Marshall OJ, Chueh AC, Wong LH, Choo KH. Neocentromeres: new insights into centromere structure, disease development, and karyotype evolution. Am J Hum Genet. 2008;82:261-82.

22. Liehr T. Small supernumerary marker chromosomes. 2015. http://ssmc-tl. com/sSMC.html. Accessed 8 Jan 2015

23. Liehr T, Claussen U, Starke H. Small supernumerary marker chromosomes (sSMC) in humans. Cytogenet Genome Res. 2004;107:55-67.

24. Murmann AE, Conrad DF, Mashek H, Curtis CA, Nicolae Rl, Ober C, et al. Inverted duplications on acentric markers: mechanism of formation. Hum Mol Genet. 2009;18:2241-56.

25. Wu D, Chi H, Shao M, Wu Y, Jin H, Wu B, et al. Prenatal diagnosis of Down syndrome using cell-free fetal DNA in amniotic fluid by quantitative fluorescent polymersase chain reaction. Chin Med J (Engl). 2014;127:1897-901.

26. Depinet TW, Zackowski JL, Earnshaw WC, Kaffe S, Sekhon GS, Stallard R, et al. Characterization of neo-centromeres in marker chromosomes lacking detectable alpha-satellite DNA. Hum Mol Genet. 1997;6:1195-204.

27. Warburton PE, Dolled M, Mahmood R, Alonso A, Li S, Naritomi K, et al. Molecular cytogenetic analysis of eight inversion duplications of human chromosome $13 \mathrm{q}$ that each contain a neocentromere. Am J Hum Genet. 2000:66:1794-806.

28. Liehr T, Utine GE, Trautmann U, Rauch A, Kuechler A, Pietrzak J, et al. Neocentric small supernumerary marker chromosomes (SSMC)-three more cases and review of the literature. Cytogenet Genome Res. 2007;118:31-7.

29. Rashidi-Nezhad A, Parvaneh N, Farzanfar F, Azimi C, Harewood L, Akrami SM, et al. 2q34-qter duplication and 4q34.2-qter deletion in a patient with developmental delay. Eur J Med Genet. 2012:55:203-10.

30. Wiszniewski W, Hunter JV, Hanchard NA, Willer JR, Shaw C, Tian Q, et al. TM4SF20 ancestral deletion and susceptibility to a pediatric disorder of early language delay and cerebral white matter hyperintensities. Am J Hum Genet. 2013:93:197-210.

31. Thomas S, Wright KJ, Le Corre S, Micalizzi A, Romani M, Abhyankar A, et al. A homozygous PDE6D mutation in Joubert syndrome impairs targeting of farnesylated INPP5E protein to the primary cilium. Hum Mutat. 2014;35:137-46.

32. Williams SR, Aldred MA, Der Kaloustian VM, Halal F, Gowans G, McLeod DR, et al. Haploinsufficiency of HDAC4 causes brachydactyly mental retardation syndrome, with brachydactyly type $\mathrm{E}$, developmental delays, and behavioral problems. Am J Hum Genet. 2010;87:219-28.

33. Hamdan FF, Gauthier J, Araki Y, Lin DT, Yoshizawa Y, Higashi K, et al. Excess of de novo deleterious mutations in genes associated with glutamatergic systems in nonsyndromic intellectual disability. Am J Hum Genet. 2011:88:306-16.

34. Klopocki E, Lohan S, Brancati F, Koll R, Brehm A, Seemann P, et al. Copy-number variations involving the $\mathrm{HH}$ locus are associated with syndactyly and craniosynostosis. Am J Hum Genet. 2011;88:70-5.

35. Levy B, Papenhausen P, Tepperberg J, Dunn T, Fallet S, Magid M, et al. Prenatal molecular cytogenetic diagnosis of partial tetrasomy 10p due to neocentromere formation in an inversion duplication analphoid marker chromosome. Cytogenet Cell Genet. 2000;91:165-70.

\section{Submit your next manuscript to BioMed Central and take full advantage of:}

- Convenient online submission

- Thorough peer review

- No space constraints or color figure charges

- Immediate publication on acceptance

- Inclusion in PubMed, CAS, Scopus and Google Scholar

- Research which is freely available for redistribution 